11

\title{
Электродинамические характеристики рупорных СВЧ антенн из графеносодержащих углекомпозитных материалов
}

\author{
(C) Н.А. Дугин, ${ }^{1}$ Т.М. Заборонкова, ${ }^{1,2}$ Е.Н. Мясников, ${ }^{3}$ Г.Р. Беляев ${ }^{3}$ \\ ${ }^{1}$ Нижегородский государственный университет им. Н.И. Лобачевского, \\ 603950 Нижний Новгород, Россия \\ ${ }^{2}$ Нижегородский государственный технический университет им. Р.Е. Алексеева, \\ 603950 Нижний Новгород, Россия \\ ${ }^{3}$ Верхневолжский государственный университет водного транспорта, \\ 603950 Нижний Новгород, Россия \\ e-mail: ndugin@yandex.ru
}

(Поступило в Редакцию 14 апреля 2017 г. В окончательной редакции 14 июня 2017 г.)

Приведены результаты исследований электродинамических характеристик рупорных антенн $L$ - и $C$-диапазонов, изготовленных из углекомпозитных материалов с графеносодержащим связующим веществом. Основное внимание уделено поляризационным характеристикам антенн $L$-диапазона с поляризационным устройством на основе круглого волновода для создания излучения с эллиптической поляризацией.

DOI: 10.21883/JTF.2018.02.45421.2294

\section{Введение}

Основными преимуществами изделий из композитных материалов при применении их в антенной конструкции и радиотехнике являются высокая прочность при низком удельном весе, практическое отсутствие коэффициента температурного расширения, большой диапазон значений проводимости, долговечность (не подверженность коррозии). Эти свойства позволяют эффективно использовать композитные материалы в создании наземных, самолетных и космических антенных конструкций [1-4]. Проведенные авторами настоящей работы исследования СВЧ устройств, изготовленных из углекомпозитных материалов (УКМ) с графеносодержащим эпоксисвязующим веществом, показали принципиальную возможность создания нового поколения антенно-фидерных устройств [5-10].

В предыдущих работах был предложен способ создания СВЧ антенн из углекомпозитного волокна [5,7], а также анализировались некоторые их характеристики $[9,10]$. Было получено, что электродинамические характеристики УКМ антенн практически идентичны соответствующим характеристикам их металлических прототипов с аналогичными геометрическими параметрами. Для модельных образцов УКМ антенн измерялись коэффициенты стоячей волны (КСВ), диаграммы направленности (ДН) и амплитудно-частотные характеристики $(\mathrm{AЧX})$, которые позволяли оценить коэффициент усиления (КУ) антенн из УКМ.

В настоящей работе рассматриваются характеристики рупорных антенн $C$-диапазона, выполненных из разных по своей структуре углекомпозитных материалов (нитей и ткани), и проводится сравнение электродинамических характеристик указанных антенн. Кроме того, подробно исследованы поляризационные свойства антенн $L$-диапазона. Предполагалось, что поляризационные характери- стики помогут выявить различия, существующие между УКМ и металлическими антеннами.

\section{1. Исследование параметров рупорных УКМ антенн $L$ - и $C$-диапазонов}

В лабораторных условиях были изготовлены и исследованы модельные образцы рупорных антенн из углекомпозитных материалов с эпоксисвязующим графеносодержащим веществом в двух СВЧ диапазонах длин волн: в $L$-диапазоне (центральная частота $1.6 \mathrm{GHz}$ ) и в $C$-диапазоне (центральная частота $5 \mathrm{GHz}$ ). Способ их изготовления из УКМ волокон подробно описан в заявке на изобретение [5].

Антенна $L$-диапазона (рис. 1) была сделана из УКМ нити методом круговой намотки с графеносодержащим

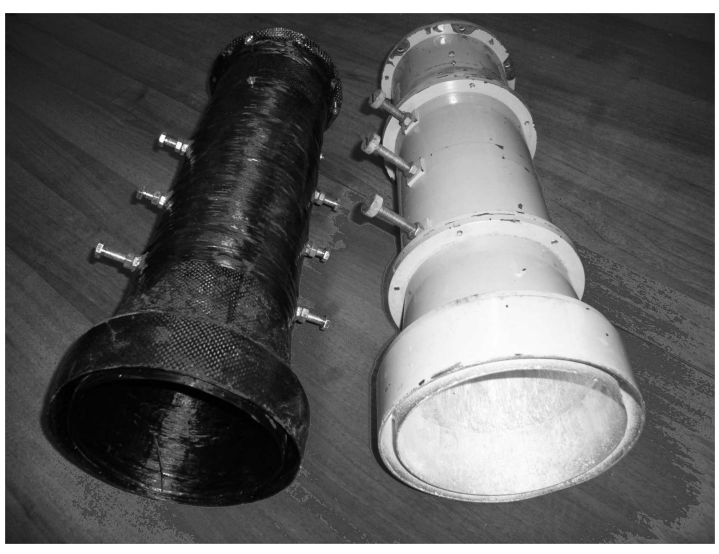

Рис. 1. УКМ антенна $L$-диапазона (слева) и металлическая антенна-аналог (справа). 


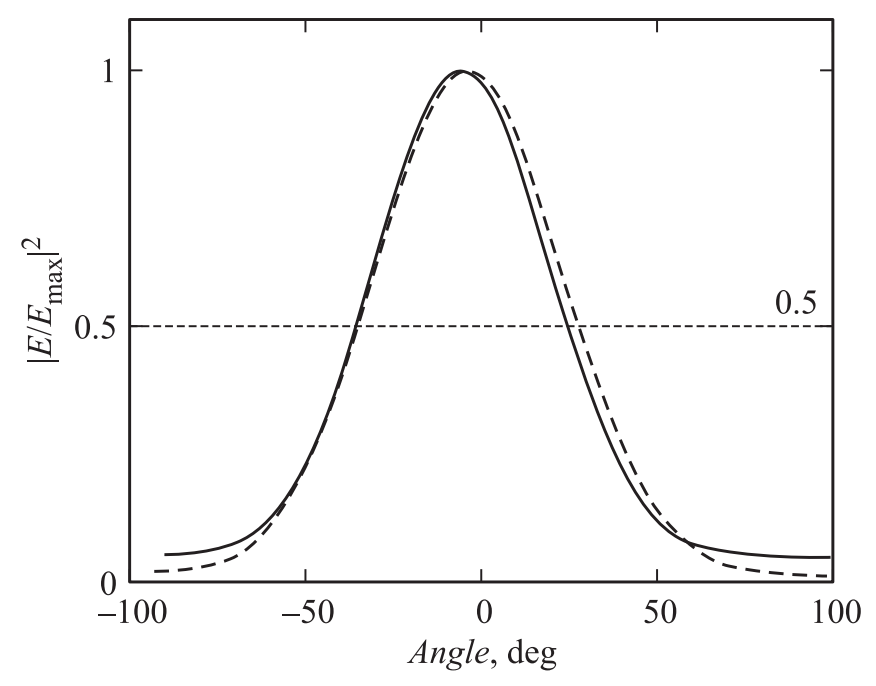

Pис. 2. Диаграмма направленности УКМ (штриховая линия) и металлической (сплошная линия) антенн.

связующим на заготовку-матрицу. Антенна имела электродинамические параметры, близкие к своему металлическому аналогу, и, таким образом, была показана принципиальная возможность применения УКМ в качестве проводящих материалов для изготовления СВЧ устройств. Для примера на рис. 2 показаны ДН (главный максимум) металлической и УКМ антенн при аппроксимации измеренных данных функцией Гаусса. Разница в полуширине аппроксимированных ДН двух антенн составляет 7\%, что не превышает ошибки измерений параметров антенн в лабораторных условиях. Абсолютные ошибки измерений в ограниченном пространстве обусловлены в основном переотражениями сигнала от стен и предметов в помещении.

Отметим, что для всех рассматриваемых в статье моделей УКМ антенн их ДН в пределах ошибок измерений совпадают с ДН металлических аналогов, и поэтому для других моделей УКМ антенн ДН не приводятся.
На частоту $5 \mathrm{GHz}$ были изготовлены два модельных образца антенны - из УКМ нити марки Zoltek Panex 35 $(50 \mathrm{~K})$ и УКМ ткани; на рис. 3 показаны УКМ антенны и их металлический аналог. Для указанных материалов можно было ожидать, что УКМ нить имеет более высокую проводимость вдоль волокон, а проводимость УКМ ткани изотропная. В качестве металлического аналога была выбрана рупорная антенна на основе круглого волновода с запиткой из двух ортогональных диполей.

В $C$-диапазоне существенное значение приобретает точность изготовления внутренней поверхности волновода. Исследуемые антенны изготовлялись методом круговой намотки УКМ на дюралевую заготовку-матрицу, точно повторяющую внутренние размеры антенны-образца. УКМ нить наматывалась на матрицу с максимальным усилием, однако для получения предельно гладкой поверхности необходимо вакуумное формование корпуса антенны. Для УКМ ткани структура поверхности волновода определялась структурой ткани (на рис. $3, b$ видно перекрестное плетение волокон). При измерении характеристик антенн $C$-диапазона использовалась волноводная секция с системой возбуждения из ортогональных диполей и настроечной пластиной, аналогичная по конструкции антенне $L$-диапазона (см. разд. 2).

Результаты измерения КСВ приведены на рис. 4. На рис. 4, $a$ изображены частотные зависимости КСВ для металлической антенны и антенны из УКМ нити, на рис. 4, $b$ - для двух УКМ антенн - из нити и ткани. Видно, что зависимость от частоты КСВ УКМ антенн более сглажена, у металлической антенны заметен резонансный характер, при этом минимальные величины КСВ для всех модификаций антенн примерно одинаковы $(1.2-1.3)$ и соответствуют практически одной частоте. Для УКМ антенн $C$-диапазона, изготовленных из разных материалов, максимальное отличие значений КСВ в выбранной полосе частот составляет 0.2 (рис. 4,b); причиной этого, кроме различия характеристик материалов, может быть изменение сопротивления контак-
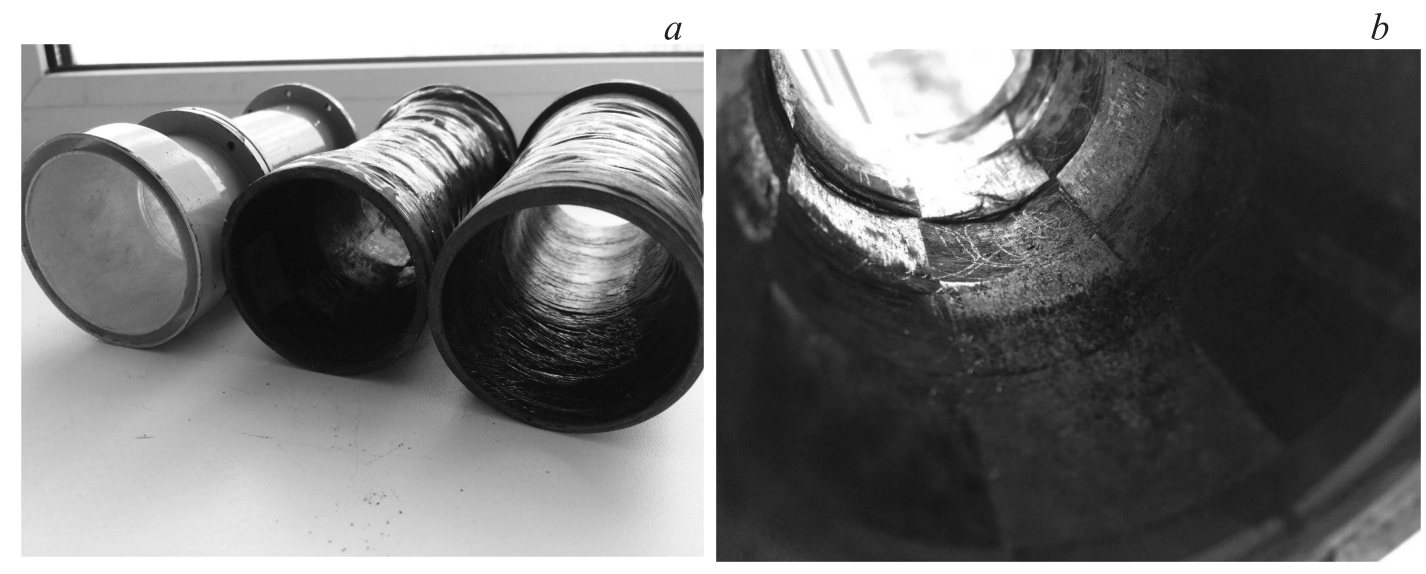

Рис. 3. Антенны $C$-диапазона из УКМ нити (справа) и УКМ ткани (в центре); металлическая антенна-аналог (слева) (a). Структура УКМ ткани $(b)$. 

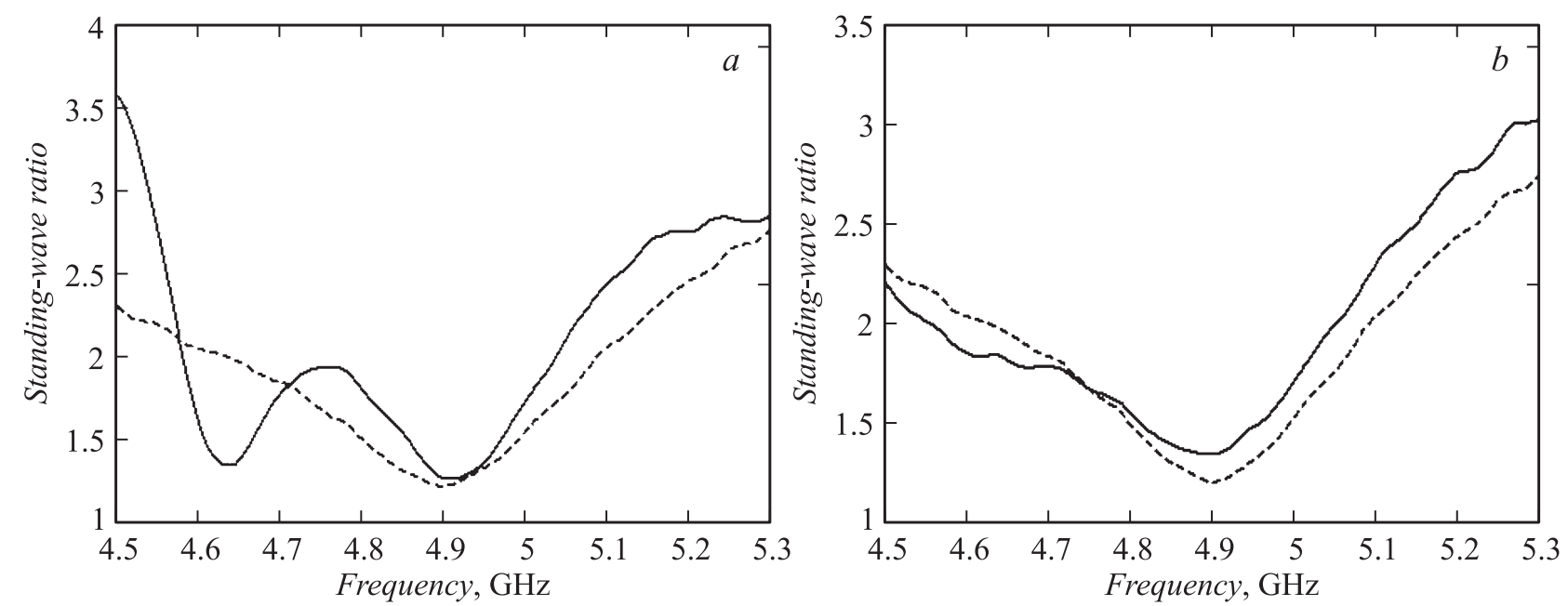

Рис. 4. КСВ металлической антенны (сплошная линия) и антенны из УКМ нити (штриховая линия) (a). КСВ антенн из УКМ нити (штриховая линия) и ткани (сплошная линия) $(b)$.

та разъемов соединительного кабеля измерительного устройства.

Аналогичный результат был получен и для антенн $L$-диапазона (см. разд. 2).

Наиболее важным параметром исследуемых антенн считается КУ, фактически характеризующий КПД, т.е. омические потери и потери на излучение. Абсолютные значения КУ не измерялись, проводилось сравнение выходных сигналов, а именно АЧХ антенн в рабочем диапазоне частот, что является достаточным для оценки эффективности УКМ антенн. На рис. 5 показаны АЧХ антенн, измеренные на вертикальной поляризации. Качественно амплитудно-частотные зависимости для всех типов антенн хорошо совпадают, „изрезанность“ характеристик определяется как особенностями системы возбуждения волноводов, так и параметрами излучающей антенны. Видно, что в нижней части диапазона усиление УКМ антенн несколько выше, в высокочастотной

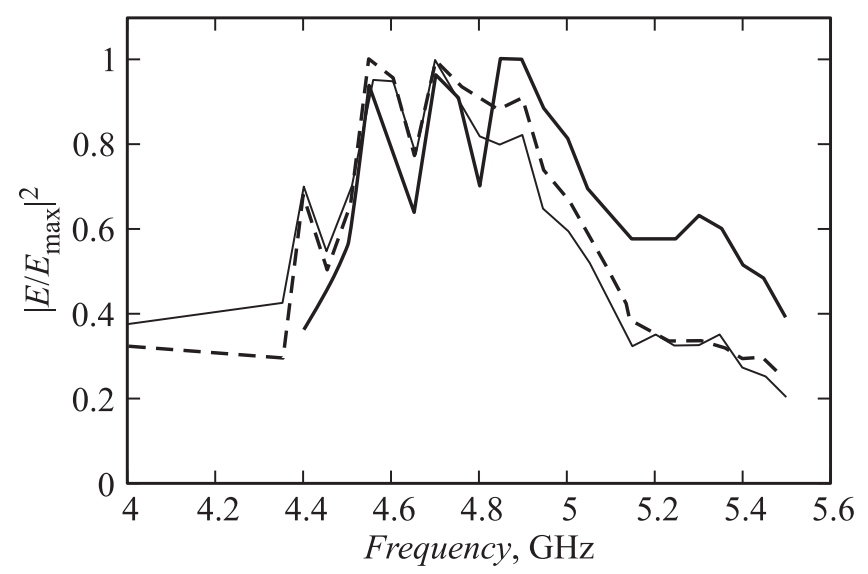

Рис. 5. АЧХ антенн: из УКМ нити (штриховая линия), из УКМ ткани (тонкая сплошная линия), металлической (жирная сплошная линия). области - наоборот. Рабочую зону можно ограничить диапазоном 4.5-5.0 GHz. Следует отметить, что для всех рупорных УКМ антенн усиление на основной рабочей частоте (по минимуму КСВ) было на $10-15 \%$ меньше, чем усиление металлических аналогов. Это обстоятельство объясняется главным образом наличием небольших омических потерь использованных композитных материалов и, возможно, способом изготовления графеносодержащего связующего.

Таким образом, в результате проведенных исследований показано, что параметры антенн из различных УКМ в пределах ошибок лабораторных измерений не отличаются друг от друга и близки к характеристикам металлической антенны-аналога. Повышение эффективности УКМ СВЧ антенн может быть достигнуто более совершенной технологией изготовления внутренней проводящей поверхности устройства и варьированием свойств графеносодержащего эпоксисвязующего.

\section{2. Методика исследования поляризационных характеристик УКМ антенны $L$-диапазона}

Такие основные характеристики УКМ антенны $L$-диапазона без поляризатора, как КСВ, ДН и АХЧ, исследованы на первом этапе работ и приведены в [7]. Далее было сделано предположение, что поляризационные характеристики антенн помогут выявить принципиальные различия между УКМ и металлическими антеннами, такие как возможное наличие анизотропной проводимости применяемых углекомпозитных материалов с графеносодержащим эпоксисвязующим, что представляет особый интерес.

С этой целью проведены исследования поляризационных характеристик УКМ антенны $L$-диапазона с поляризационным устройством на основе круглого волновода 

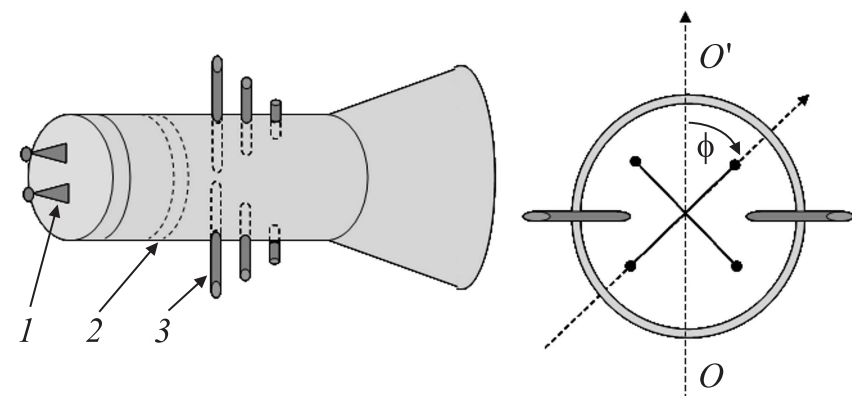

Рис. 6. Схема возбуждения и настройки рупорной антенны.

для создания излучения с эллиптической поляризацией. Введение с помощью шести штырей последовательного фазового сдвига в распространяющейся в волноводе волне должно выявить влияние на величину коэффициента эллиптичности анизотропии проводимости стенок, если она имеет существенную величину. Причиной такого изменения коэффициента эллиптичности могут быть, например, различные величины затухания для волн левой и правой круговой поляризации, обусловленные спиральной намоткой углекомпозитных нитей.

Вид УКМ антенны на $1.6 \mathrm{GHz}$ с поляризатором и ее металлического аналога показан на рис. 1; схема возбуждения и настройки антенны приведена на рис. 6. Возбуждающее устройство 1 состоит из двух ортогональных диполей, повернутых на $45^{\circ}$ относительно штырей поляризатора 3. Вид антенны вдоль оси волновода показан на рис. 6 (справа); отсчет угла $\phi$ при измерениях проводился от вертикальной линии $\mathrm{OO}^{\prime}$. Для предварительной (без штырей) настройки антенн использовались согласующие пластины из оргстекла 2 , расположенные между диполями и первыми штырями поляризатора.
Коэффициенты стоячей волны двух антенн с поляризаторами и без них измерялись на двух ортогональных поляризациях (P1, Р2). На рис. 7 показаны зависимости КСВ от частоты для поляризации Р1 (для Р2 графики имеют аналогичный вид). Видно, что в обоих случаях для металлической антенны частотная зависимость КСВ по мере удаления от центральной (рабочей) частоты имеет резонансный характер, обусловленный, по-видимому, интерференцией сигналов, отраженных от настроечных элементов и раскрыва рупора. Для УКМ антенны интерференция практически отсутствует, что может свидетельствовать о малой амплитуде отраженного от раскрыва антенны сигнала. Такое поведение КСВ может быть обусловлено более высоким затуханием в УКМ волноводе по сравнению с металлическим.

Из рис. 7 следует, что рабочая зона (значение КСВ менее 1.4) для обеих антенн без штырей поляризаторов 3 примерно одинакова $(1.58-1.7 \mathrm{GHz})$, минимальные значения КСВ порядка 1.1. Для антенн с поляризаторами видно, что характер зависимости КСВ от частоты сохранился, рабочие зоны несколько сместились, минимальные значения КСВ также порядка 1.1.

Исследования поляризационных характеристик УКМ антенны и ее металлического аналога проводились в лабораторных условиях методом вращения линейнополяризованной излучающей антенны вокруг ее продольной оси. В качестве излучателя сигнала использовался генератор R\&S SMB 100A и эталонная антенна П6-23А на опорно-поворотном устройстве с тремя степенями свободы; для измерения уровня принимаемого сигнала использовался радиометр ПК7-17. При отсутствии штырей поляризационная зависимость выходного сигнала от угла поворота, как и следовало ожидать, близка к синусоидальной (в соответствии с законом Малюса), что свидетельствует о линейной поляризации исследуемых антенн. Для исследований поляризационных
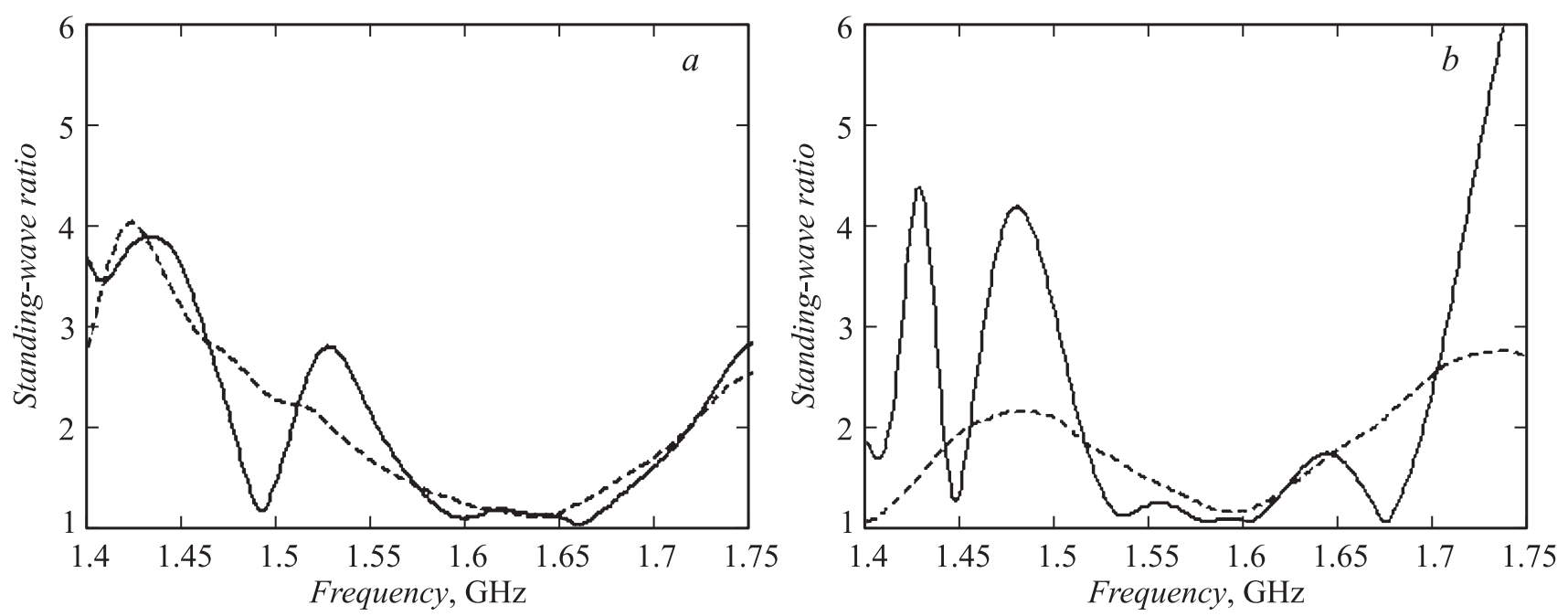

Рис. 7. КСВ антенн без поляризационных элементов $(a)$; с поляризатором $(b)$ (штриховая линия - КСВ УКМ антенны, сплошная линия - КСВ металлической). 

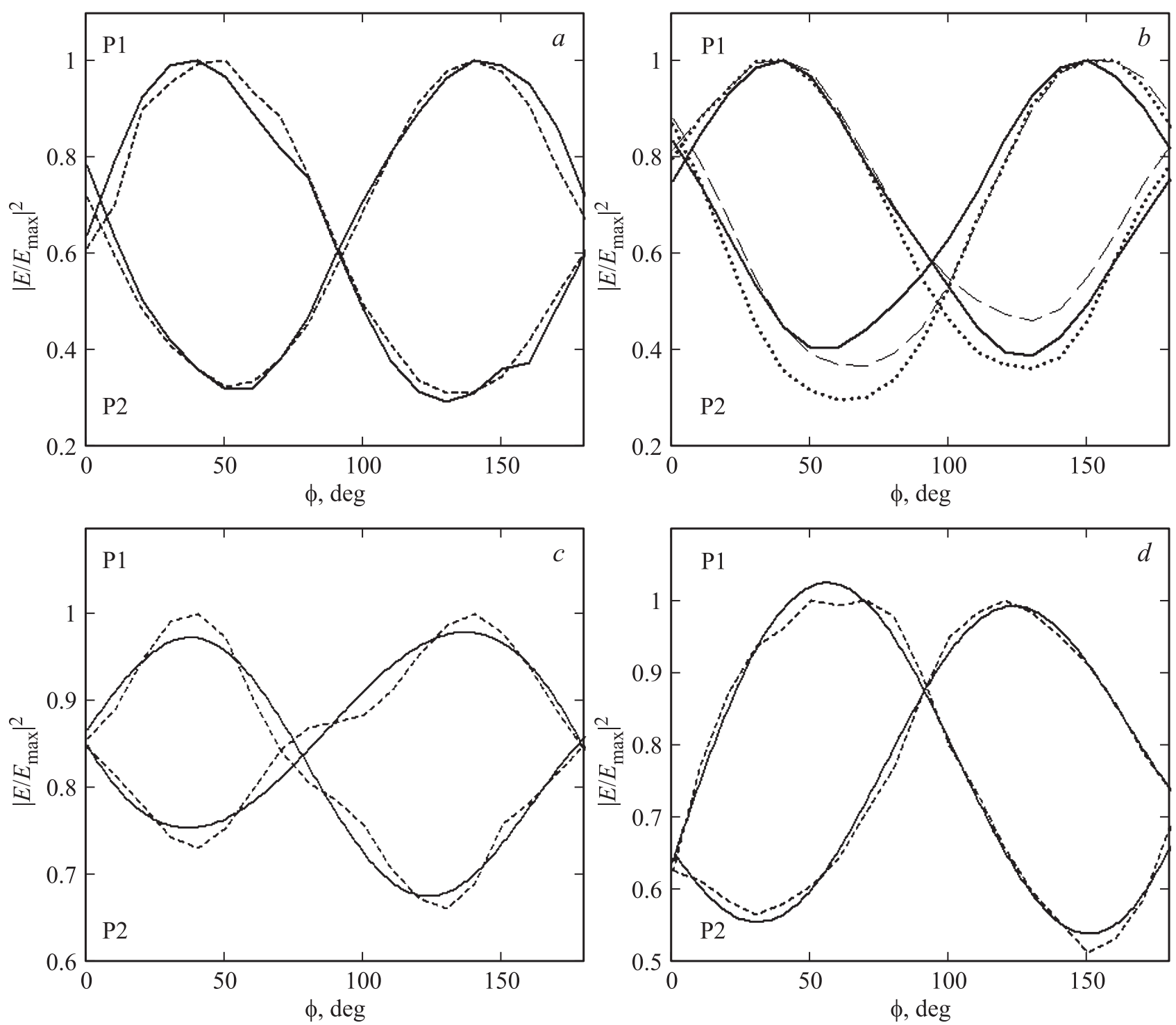

Рис. 8. Амплитуда сигнала УКМ антенны от угла поворота $\phi$ излучающей антенны для двух типов поляризации на частотах: $a-1.55$ (сплошная линия) и $1.575 \mathrm{GHz}$ (штриховая линия); $b-1.6$ (сплошная линия), 1.625 (штриховая линия) и $1.64 \mathrm{GHz}$ (пунктирная линия). Амплитуды сигнала металлической антенны от угла поворота излучающей антенны для двух типов поляризации (пунктирная линия соответствует данным измерения, сплошная - аппроксимированным данным) на частотах: $c-$ $1.55, d-1.6 \mathrm{GHz}$.

характеристик были выбраны пять частот в диапазоне $1.55-1.65 \mathrm{GHz}$.

\section{3. Результаты измерений поляризационных характеристик УКМ антенны $L$-диапазона}

Ниже приведем некоторые результаты измерений поляризационных характеристик двух антенн при наличии у них штырей поляризаторов 3: для УКМ антенны (рис. 8, $a, b$ ) и металлической (рис. $8, c, d$ ). На рис. 8, $a$ показаны зависимости нормированной амплитуды сигнала УКМ антенны на двух поляризациях от угла поворота излучающей антенны на частотах 1.55 и $1.575 \mathrm{GHz}$; на рис. $8, b-$ на частотах $1.6,1.625$ и $1.64 \mathrm{GHz}$. Отметим, что в аппроксимации измеренных данных необходимости не было.

На рис. $8 c, d$ приведены зависимости нормированной амплитуды сигнала металлической антенны от угла поворота плоскости поляризации излучающей антенны на частотах 1.55 и $1.6 \mathrm{GHz}$.

Из приведенных графиков видно, что зависимости амплитуды принимаемого сигнала от угла поворота плоскости поляризации излучающей антенны для УКМ антенны более гладкие (практически синусоидальные), коэффициент эллиптичности $K_{\mathrm{ell}}$ (отношение минимума сигнала к максимуму) близок к 0.4 и слабо зависит 

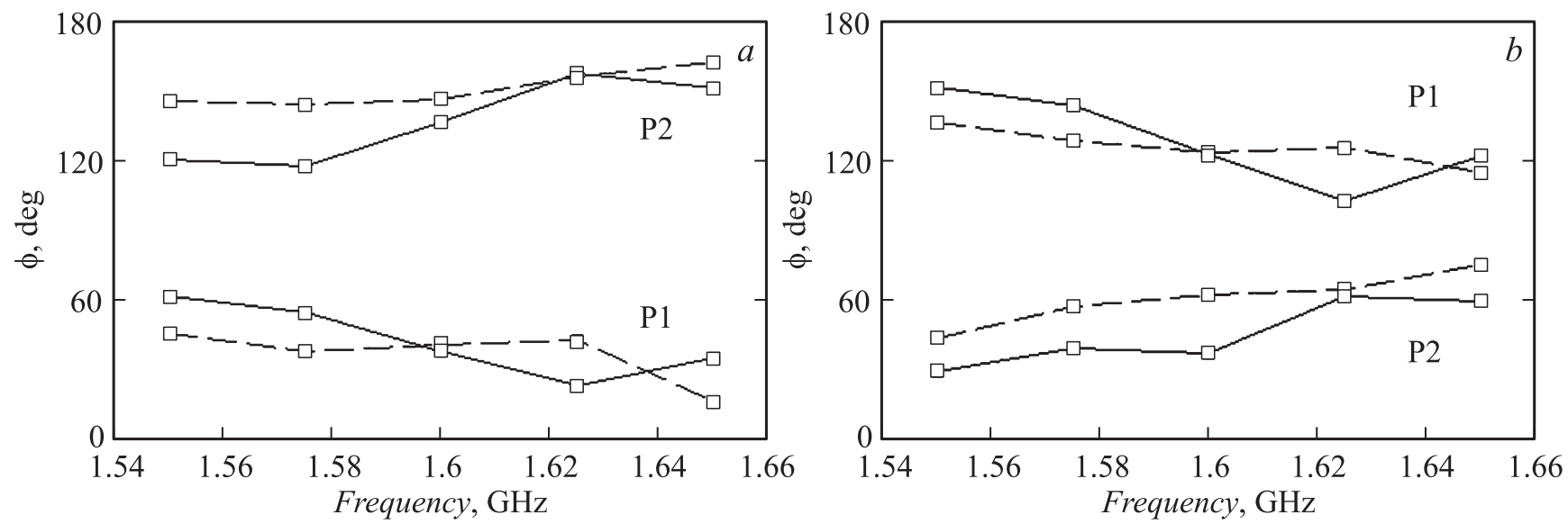

Рис. 9. Зависимость угловых координат $\phi$ максимумов $(a)$ и минимумов $(b)$ поляризационных эллипсов от частоты: для УКМ (штриховая линия) и металлической (сплошная линия) антенн.

от частоты. Для металлической антенны коэффициент эллиптичности меняется в пределах 0.55-0.8 и максимален в центре рабочего диапазона; кроме того, на этих частотах сигнал нестабилен по амплитуде.

Поляризационные эллипсы электромагнитных волн в двух антеннах имеют некоторые различия в величине $K_{\text {ell }}$ и в ориентации. На рис. 9 показаны зависимости от частоты угловых координат максимумов (рис. 9, $a$ ) и минимумов (рис. 9, b) поляризационных эллипсов для УКМ и металлической антенн для двух поляризаций Р1 и Р2. Можно считать, что в пределах ошибок измерений, тенденции изменения ориентации эллипсов от частоты (увеличение или уменьшение значений координат экстремумов) одинаковы для обеих антенн. Этот эффект определяется, скорее всего, индивидуальными особенностями штырей поляризаторов и системы настройки антенн (возбуждающие диполи были одними и теми же).

Таким образом, выявленные различия между УКМ и металлической антеннами определяются только величиной $K_{\text {ell }}$, что позволяет предположить возможное наличие анизотропной проводимости стенок волновода, влияющей на распространение волны в УКМ волноводе.

\section{Заключение}

На основании исследования характеристик СВЧ антенн УКМ были получены следующие результаты:

- для всех рассматриваемых в настоящей работе моделей УКМ антенн их диаграммы направленности в пределах ошибок измерений совпадают с ДН металлических аналогов;

- зависимость коэффициентов стоячей волны УКМ антенн более сглажена по сравнению с КСВ металлического аналога, т.е. можно считать ее более широкополосной;

- коэффициент эллиптичности УКМ антенны в диапазоне $1.5-1.65 \mathrm{GHz}$ лежит в пределах 0.35-0.45 и в 1.5-2 раза меньше, чем у металлического аналога. Это обстоятельство позволяет предположить возможное наличие неизотропности проводимости УКМ стенок круглого волновода, являющегося одной из основных частей конструкции исследуемой рупорной антенны.

Для того чтобы более достоверно определить наличие анизотропной проводимости поверхности антенн и СВЧ устройств из УКМ, в дальнейшем планируется исследование коэффициента эллиптичности УКМ антенны $C$-диапазона. В случае подтверждения наличия анизотропной проводимости у СВЧ антенн, изготовленных из УКМ, это свойство можно будет использовать для формирования нужных характеристик УКМ радиотехнических устройств.

Авторы выражают благодарность В.И. Абрамову за ценные обсуждения рассмотренной проблемы и М.Б. Нечаевой за помощь в работе. Работа выполнена при поддержке Российского научного фонда (проект № 14-12-00510). Исследования ведутся при финансовой поддержке Минобрнауки (госзадание № 3.2722.2017/4.6).

\section{Список литературы}

[1] Овечкин Г.И., Голованова В.В., Двирный Г.В. и др. Трансформируемая антенна зонтичного типа космического аппарата. Патент на изобретение. RU2427949.

[2] Бычков И.В., Зотов И.С., Федий А.А. // Письма в ЖТФ. 2011. Т. 37. Вып. 14. С. 90-94.

[3] Рыбин В.В., Кузнецов П.А., Улин И.В., Фармаковский Б.В., Бахарева В.Е. // Вопросы материаловедения. 2006. № 1 (45). C. 169-178.

[4] Dugin N.A., Zaboronkova T.M., Chugurin V.V., Myasnikov E.N. // The 21 Annual Intern. Conf. on Advanced Laser Technologies (ALT'-13). 2013. P. 192.

[5] Дугин Н.А., Заборонкова Т.М., Мясников Е.Н., Чугурин B.B. Антенно-фидерное СВЧ устройство из углеком- 
позитного материала и способ его изготовления. Патент на изобретение № 2577918 (RU 2577918 C1) от 20.03.2016. Бюлл. № 8 .

[6] Дугин Н.А., Заборонкова Т.М., Мясников Е.Н., Чугурин B.B. // Труды 15-го Международного научно-промышленного форума „Великие реки - 2013“. Т. 2. Н. Новгород: Изд-во ФБОУ ВПО „ВГАВТ“, 2013. C. 356-358.

[7] Zaboronkova T.M., Dugin N.A., Myasnikov E.N. // Proc. of the $9^{\text {th }}$ Europ. Conf. on Antennas and Propagation (EuCAP'2015). 2015. P. 72282201-1-7228220-2.

[8] Дугин Н.А., Беляев Г.Р. // Труды 17-го Международного научно-промышленного форума „Великие реки - 2015“. Н.Новгород: Изд-во ФБОУ ВПО „ВГУВТ“, 2015. Т. 2. С. 244-247.

[9] Дугин Н.А., Заборонкова Т.М., Мясников Е.Н. // Письма в ЖТФ. 2016. Т. 42. Вып. 11. С. 91-96.

[10] Dugin N.A., Zaboronkova T.M., Myasnikov E.N. // Latvian J. Phys. Techn. Sci. 2016. Vol. 5. P. 17-23. 